\title{
The Influence of the Tutorial activity in the academic, didactic and social development
} of the tutors of biochemistry at UFV.

\author{
Baracat-Pereira, M.C. ${ }^{1,2}$; Carvalho, A.M.X. ${ }^{1}$; Mendes, F.Q. ${ }^{1}$; Sartori, M.A. ${ }^{1}$; Costa, T.R. ${ }^{1}$; Pereira, \\ H.J.V. ${ }^{1}$; Pinho, T.A. ${ }^{1}$; Marinho, P.E.A. ${ }^{1}$; Silva, J.C. ${ }^{1}$; Teixeira, F.R. ${ }^{1}$; Braathen, P.C. ${ }^{1,3}$
}

Programa de Tutoria ${ }^{1}$, Depto. Bioquímica e Biologia Molecular ${ }^{2}$; Depto. Química ${ }^{3}$, Universidade Federal de Viçosa (UFV), Viçosa, MG.

The Tutorial Program in Biochemistry, implemented at UFV in 2000, is characterized by the actuation of the students as tutors, seeking to level the prior knowledge among students of biochemistry. The tutors, official or volunteer, are under graduated students (tutor I) and post-graduated students (tutor II). The aim of this study was to show the profile of a tutor of biochemistry and its influence in his academic, didactic and social development. A questionnaire of 31 questions was answered by tutors that acted between 2000 and 2004, and the main comments were detached. From 29 tutors who frequented the program during the period ( 5 tutors II and 24 tutors I), 19 answered the questionnaire. The average time of permanence of the tutors in this program was 9 months, varying from 4 to 28 months. Fourteen from the 19 students that worked as tutors chose to act in the program for the possibility of teaching and also helped them to be more extroverted and they felt satisfied to help other people which contributes effectively for the training of the ones who want to follow the academic career. It also contributes professionally by increasing the capacity of relationship in group, dynamism, decisions and organization, characteristics that are more and more appraised in the job market. It was verified that the studies of the tutors were modified by the necessity of preparing the classes because to teach, you need to understand the subject and you need to present it to the student in the best way, you have to consider the life and the previous knowledge of the student. To all of them, the program helped them to improve the oratory and your organization and develops a sense of professional responsibility, assiduity and punctuality. In general, the Tutorial Program has contributed for the professional, personal and social maturity of the tutors, corresponding to an ample and satisfactory experience for the human development of these students. 